Est Ag 48 (2013) 47-67

\title{
La pedagogía agustiniana en la formación
}

\author{
C. Totumo, OSA*
}

RESUMEN: El propósito de esta reflexión es analizar los rasgos característicos del ideario pedagógico propuesto por san Agustín, expuestos en mi libro Aproximación al ideario pedagógico de san Agustín, para presentarlos como medios necesarios no sólo para la educación formal, sino también para la formación de los candidatos a la vida religiosa agustiniana. La pedagogía agustiniana es una propuesta cristiana de humanización a la luz de la formación académica y experiencia espiritual de san Agustín. En esta pedagogía, el diálogo es esencial porque facilita la interacción del hombre consigo mismo, con los demás (docente o formador), con sus compañeros, los cuales son considerados sus condiscípulos, y con Dios. La base sobre la que se sustenta esta investigación es doble: antropológica (el hombre) y teológica (Dios), concretizada en un dinamismo espiritual humanizador. Descriptores: Pedagogía agustiniana; Diálogo pedagógico; Interioridad, Espiritualidad, Comunidad.

ABSTRACT: The purpose of this study is to analyze the characteristics of pedagogical ideas proponed by St. Augustine, exposed in my book Approaching the educational ideals of St. Augustine, to present them as means not only formal education but also to the formation of candidates to the Augustinian religious life. Augustinian Pedagogy is a Christian proposal of humanization in the light of the academic and spiritual experience of St. Augustine. In this pedagogy, dialogue is essential because it facilitates the interaction of man with himself, with others (teachers and trainers), with peers, with are considered his classmates, and with God. The basis of this research is founded in twofold: anthropological (man) and theological (God) concretized in a humanizing spiritual dynamism. Key words: Augustinian pedagogy, pedagogical dialogue, Interiority, Spirituality, Community.

* carlostotumo@gmail.com 
La finalidad de estas líneas es ver qué elementos de la pedagogía agustiniana pueden ayudarnos en el desarrollo de nuestros procesos formativos. Sin embargo, debo hacer expreso un posible error hermenéutico implícito en esta pregunta, el cual consiste en comprender la pedagogía agustiniana como algo exclusivo de nuestras instituciones educativas y totalmente distinta a nuestros procesos formativos.

La pedagogía agustiniana es una propuesta cristiana de humanización a la luz de la formación académica y experiencia espiritual de san Agustín. Es un proceso hermenéutico existencial y vital que Agustín desarrolla para comprenderse a sí mismo y, por ende, a los demás, ya que él es humano y nada de lo humano le es ajeno (Cf. Carta, 78, 8). En consecuencia, nuestras instituciones educativas y nuestras casas de formación son dos ámbitos de aplicación de esta propuesta de interiorización elevada a la trascendencia y concretizada en las relaciones interpersonales de fraternidad. Esto se puede ver en las palabras de Agustín cuando afirma en los Soliloquios que lo único que desea es "Conocer a Dios y al alma" (I, II, 7). Pero la conjugación copulativa "y" debe entenderse como inclusiva y no como excluyente. Por tanto, en términos contemporáneos se podría afirmar que Agustín pretende hacer una teología antropológica o una antropología teológica, ya que Dios y el hombre están en relación continua. Idea que se puede ver claramente en el párrafo de las Confesiones en donde el santo de Hipona expresa que la razón por la cual no encontraba a Dios era porque él no estaba consigo mismo (Cf. X, XXVII, 38). "Dios es más íntimo que nuestra propia intimidad y más alto que los más alto de nuestro ser" (Las confesiones, III, VI, 11). Por ende, desde esta perspectiva, para llegar a Dios el hombre debe llegar primero a sí mismo.

La pedagogía agustiniana está en perfecta concordancia con la concepción educativa contemporánea, la cual sostiene que la educación es un proceso intencional o espontáneo de transmisión de contenidos teórico-prácticos que tiene como finalidad lograr cambios de comportamiento, conocimientos y técnicas para el abordaje de la realidad (Freire, 1997). Es, por tanto, un proceso bidireccional entre enseñante y aprendiz, y aprendices entre sí. En él se desarrollan múltiples relaciones interpersonales orientadas al desarrollo existencial de los sujetos que interactúan. En el siguiente gráfico se esquematiza esta concepción contemporánea de la educación. 


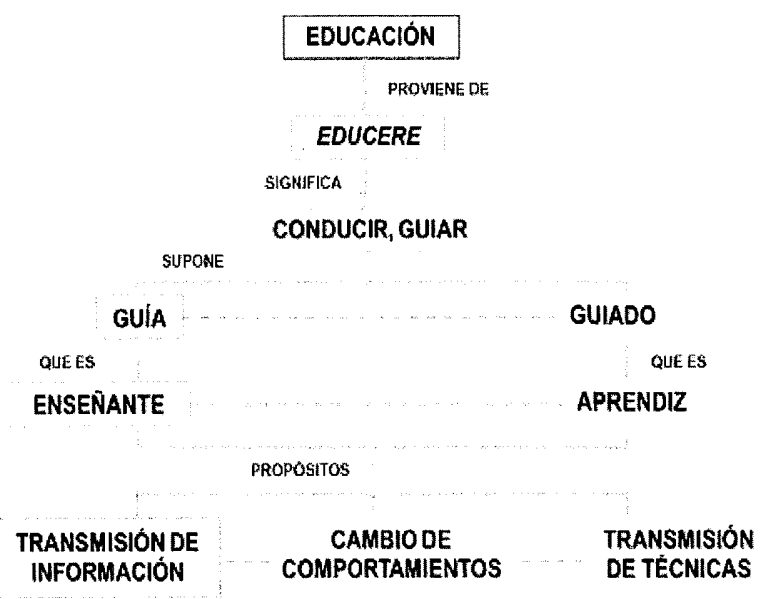

Gráfico $N^{\circ} 1$. Concepción contemporánea de la Educación (Totumo, C., 2012)

Debido a que la finalidad de la pedagogía agustiniana es potenciar un proceso humanizador, el punto de partida de esta pedagogía es netamente antropológico. La visión particular que se tenga del hombre determinará la perspectiva formativa y la propuesta pedagógica que se adopte. Todo proceso formativo tiende a ser consecuente con la visión y apreciación que se tenga del ser humano.

En consecuencia, el desarrollo del tema que nos ocupa partirá de una exposición general de la antropología agustiniana para, posteriormente, ver cuál es la concepción formativa que emana de esta antropología. En tercer lugar, se expondrán algunos elementos pedagógicos que median entre estas dos concepciones agustinianas, a saber, la antropológica y la formativa. Por último, se desarrollará una propuesta de espiritualidad agustiniana como sustento a todo el proceso humanizador planteado. Para Agustín es el Espíritu de Cristo quien nos ayuda a llegar a nosotros mismos y a Dios. No somos nosotros mismos con nuestras propias fuerzas, como afirma Pelagio.

\section{Concepción antropológica agustiniana}

El hombre es, según Agustín, "Una substancia racional que consta inseparablemente de alma y cuerpo" (Tratado sobre la Trinidad, XV, VII, 11). El alma es el principio vital del cuerpo, al que preserva y mantiene en unidad. Es un alma racional ya que en ella actúan las facultades superiores del hombre: el pensa- 
miento y la inteligencia (Rodríguez, 1978). El cuerpo, por su parte, es la dimensión que el hombre comparte con los animales: los instintos y la sensación. Es importante subrayar que esta distinción es sólo teórica más no óntica, ya que:

El hombre no es el cuerpo solo ni el alma sola, sino el compuesto de alma y cuerpo. El alma no es todo el hombre, sino su parte principal; ni el cuerpo es todo el hombre, sino su parte inferior. El conjunto de uno y otro es lo que recibe el nombre de "hombre" (La ciudad de Dios, XIII, XXIV, 2).

En consideración a estas palabras de Agustín, se puede afirmar que el hombre es un "cuerpo espiritualizado" o un "espíritu encarnado" debido a que alma y cuerpo son dos elementos de una única realidad: el hombre. Por consiguiente, toda propuesta que tenga la finalidad de potenciar el desarrollo humano debe atender a estos dos elementos interrelacionados. Todo verdadero desarrollo humano ha de ser holístico e integral. Es decir, debe atender todas las dimensiones del ser humano, pero no de manera aislada, sino desde una integración.

El hombre no es una realidad "ya hecha”. Es un ser dinámico y una posibilidad siempre abierta. El hombre está inmerso en un profundo dinamismo existencial (Cf. Las confesiones, I, I, 1). Es un ser buscador apasionado de la Verdad, la cual llega a vislumbrar, pero nunca alcanzar en su totalidad (Cf. Tratado sobre la Trinidad, XI, I, 1; XV, II, 2). La inquietud existencial y el consiguiente afán y empeño por hallar la Verdad apetecida, le impulsan a volcarse hacia el interior de sí mismo porque es allí donde se le puede encontrar (Cf. La verdadera religión, XXXIX, 72; El maestro, XI, 38; XII, 39).

Cada ser humano debe ir determinándose desde su propia originalidad, es decir, desde sus potencialidades. Cada hombre llega a este mundo como un "potencial viviente", listo para ser dinamizado y actualizado (Berdón, 2008). Por consiguiente, es condición necesaria que el hombre entre a su interior para conocer el cúmulo de riqueza que le es propio y poder, así, ir auto-determinándose. $\mathrm{Al}$ respecto, Agustín exclama: “Cuántas riquezas no oculta el hombre dentro de sí! Pero, ¿de qué le sirven si no sondea e investiga?" (Comentario al Salmo, 76, 9).

El hombre se construye como tal no desde la exterioridad, sino desde su mundo interior. El hombre autónomo es aquel que vive desde una "interioridad exteriorizada", es decir, el que vive y se relaciona desde lo que es. Agustín invita al hombre a no ir afuera, a regresar dentro de sí mismo porque la verdad habita en el "hombre interior" (La verdadera religión, XXXIX, 72). "Andar por dentro es desear las cosas de dentro. Andar por fuera es desechar las cosas de dentro y llenarse de las de fuera" (Tratados sobre el Evangelio de San Juan, XXV, 15). 
Para Agustín, el hombre necesita volver a sí mismo para poder encontrar lo que es, no lo que los otros quieren que sea (Rodríguez, 1978). Esto no significa ensimismarse o aislarse de los otros, sino vivir con los otros en autenticidad. Lo exterior al hombre puede ser una ayuda para que éste pueda descubrir sus potencialidades y actualizarlas para vivir en autenticidad y autonomía. Por tanto, Agustín propone el paso del Hombre exterior al Hombre Interior. Los términos exterior e interior hacen referencia al hombre mismo. En el siguiente cuadro comparativo expondré cinco características esenciales a estos dos modelos antropológicos.

\begin{tabular}{|l|l|}
\hline \multicolumn{1}{|c|}{ Hombre Exterior } & \multicolumn{1}{c|}{ Hombre Interior } \\
\hline $\begin{array}{l}\text { 1. Incluye cuanto nos es común con el } \\
\text { animal: cuerpo (sensaciones e insttintos) }\end{array}$ & $\begin{array}{l}\text { 1. Es netamente espiritual: irreductible a } \\
\text { la materia. }\end{array}$ \\
\hline $\begin{array}{l}\text { 2. Es objeto de su propia historia: es lo } \\
\text { que ha sido su pasado, registrado en su } \\
\text { memoria. }\end{array}$ & $\begin{array}{l}\text { 2. Es sujeto propio vivir: capaz de auto- } \\
\text { crearse a sí mismo en cada instante. }\end{array}$ \\
\hline $\begin{array}{l}\text { 3. Crece por adquisición de fuera aden- } \\
\text { tro: Vale en la medida y calidad de lo } \\
\text { que adquiere. }\end{array}$ & $\begin{array}{l}\text { 3- Crece por autoexpansión de dentro } \\
\text { afuera. Vale por lo que Es, o está llama- } \\
\text { do a SER. }\end{array}$ \\
\hline $\begin{array}{l}\text { 4. Orientación: CENTRÍPETA. Todo lo } \\
\text { aprecia y valora en referencia al propio } \\
\text { Yo. }\end{array}$ & $\begin{array}{l}\text { 4. Orientación básica: IRRADIANTE. } \\
\text { Es y se comporta así porque ese es su } \\
\text { "misterio". }\end{array}$ \\
\hline $\begin{array}{l}\text { 5. Es la respuesra a la pregunta: ¿QUÉ } \\
\text { soy yo? }\end{array}$ & $\begin{array}{l}\text { 5. Es la respuesta a la pregunta: ¿QUIÉN } \\
\text { soy yo? }\end{array}$ \\
\hline
\end{tabular}

Desde esta perspectiva, todos los seres humanos estamos inmersos en un proceso vital de construcción de nuestra existencia. Digo "vital" porque es un proceso que culmina con la muerte. Por tanto, en los procesos formativos de nuestra Orden hay que afirmar que no solamente los formandos están inmersos en un proceso de formación; los que denominados formadores también lo están. El error común es pensar que estos últimos ya están formados, lo cual implicaría su muerte. Anquilosarse en la construcción de la existencia es morir (Cf. Sermón, 169, 18). Nuestra Orden expresa esta idea a través de lo que se denomina Formación Permanente, en donde la Formación Inicial es solamente una etapa de ésta. El proceso formativo agustiniano debe desarrollarse en un proceso de múltiples relaciones: formador-formandos y formandos entre sí. 
Agustín sostiene las relaciones múltiples de relación en el proceso existencial porque el hombre es en relación. "Necesitamos de los demás para ser nosotros mismos" (Comentario al salmo, 125, 13). Por ello, el Santo expresa claramente su concepción humanista al afirmar que por el hecho de ser hombre "Nada de lo humano le es ajeno" (Carta, 78,8). Además, sostiene que el hombre es un ser social, ya que está ligado por un vínculo natural a una sociedad (Cf. El orden, II, XII, 35). Desde esta perspectiva, el hombre está inmerso en una constante búsqueda de sentido existencial a través de un proceso dinámico y dialógico de reflexión. Para Agustín, el verdadero conocimiento consiste en conocerse a sí mismo. El conocimiento del mundo y de las cosas solamente tienen sentido en tanto contribuyan al primero. Agustín escribe al respecto que:

Los hombres salen a hacer turismo para admirar las crestas de los montes, el oleaje proceloso de los mares, el fácil y copioso curso de los ríos, las revoluciones y los giros de los astros. Y, sin embargo, se pasan de largo a sí mismos (Las confesiones, X, VIII, 15).

En consecuencia, para Agustín no es lo mismo ser racional que ser sabio. $\mathrm{El}$ "racional" es aquel que conoce y almacena un vasto conocimiento en su memoria, pero sin ninguna repercusión de éste en la vida del sujeto que los posee. Por el contrario, el hombre "sabio" es aquel que se conoce a sí mismo, y desde su interioridad conoce y aprende todo lo demás. Al respecto, Agustín expresa que "Llamamos sabios a quienes... mediante el gobierno de su espíritu, han conquistado la paz" (El libre albedrío, I, 69).

De acuerdo con estas consideraciones de Agustín sobre el valor, la nobleza y la vocación del ser humano, hay que sostener que el hombre no es un "objeto" sino un "sujeto", no es "algo" sino "alguien". Es un ser libre y autónomo, llamado a desarrollar sus potencialidades humanas y a ser autodeterminante de sus propias acciones. Agustín afirma al respecto que "No son los ojos los que ven, sino alguien que ve por los ojos. Levántale, despiértale" (Sermón, 126, 3). El hombre es una plenitud potencial llamada a dinamizarse.

En este sentido, la finalidad de la formación es, para San Agustín, un medio para "despertar" y estimular al sujeto a que se "levante" e inicie un proceso de exploración y conocimiento interior. Se ha de formar para la libertad y la autonomía invitando al sujeto a vivir de manera consciente lo que profundamente ya es: ser humano.

Sin embargo, el proceso de construcción del ser humano no se agota en una dimensión horizontal, ya que éste ha sido creado por y para Dios. Esto se puede ver en la célebre frase con la cual Agustín termina el primer párrafo de sus Confesiones: "Nos has creado orientados hacia Ti, y nuestro corazón esta- 
rá inquieto hasta que descanse en Ti" $(\mathrm{I}, \mathrm{I}, 1)$. Esta frase expresa tres afirmaciones esenciales que determinan el pensar agustiniano: (a) el hombre tiene un origen creatural: nos has creado; (b) un dinamismo existencial: nuestro corazón estará inquieto; y (c) una orientación creatural: hacia Ti - hasta que descanse en Ti. En consecuencia, la construcción del ser humano nunca será integral si se deja de lado su dimensión trascendente. Y como a Dios se le busca con el ánimo de encontrarlo y se le encuentra con el ánimo de buscarlo, este proceso de humanización es algo vital y debe estar acompañado por una sana espiritualidad debido a que es el Espíritu quien nos ayuda a alcanzar nuestro orden (Cf. Las confesiones, XIII, VII, 8; XIII, IX, 9). El último apartado de esta ponencia será dedicado al desarrollo de una propuesta de espiritualidad agustiniana.

A modo de resumen, en la siguiente página se presenta un gráfico con los elementos pedagógicos agustinianos y el proceso humanizador propuesto.

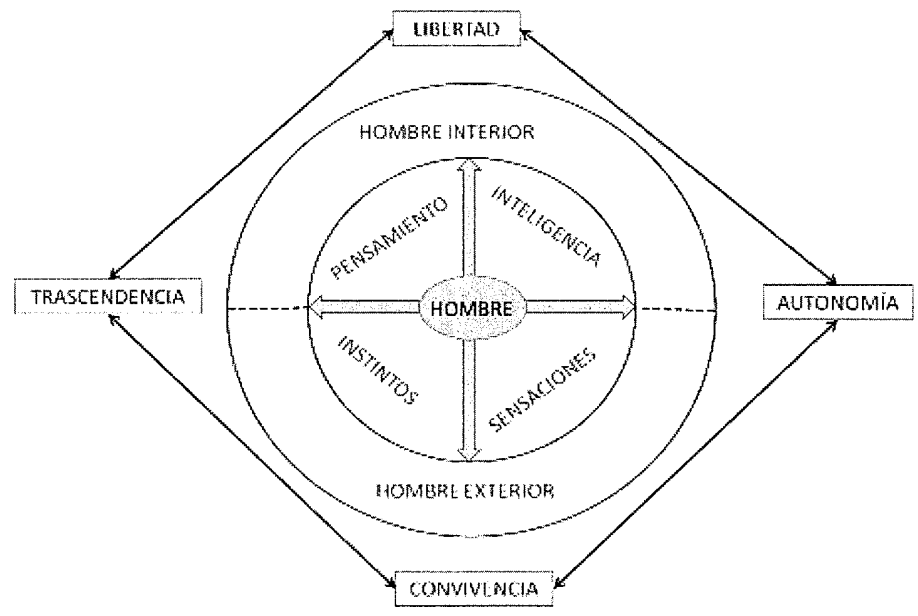

Gráfico $N^{\circ}$ 2. Antropología agustiniana (Totumo, C., 2012)

\section{Concepción formativa agustiniana}

Desde la concepción antropológica agustiniana desarrollada en el apartado anterior se puede sostener que para Agustín el proceso formativo es netamente inductivo y consiste en un conocimiento y diálogo profundo y horizontal entre formador y formando, y formandos entre sí. Por tanto, es necesario que el formador cree un clima de confianza, amistad y libertad que anime 
y fomente el trabajo personal. Formador y formando han de embarcarse como condiscípulos en una misma aventura con los mismos fines y objetivos: creación de sus existencias en relación fraterna y orientada hacia Dios.

El dinamismo formativo agustiniano no consiste sólo en transmitir unos contenidos académicos, ya sean filosóficos o teológicos, sino en asumir un estilo de vida que compromete a toda la persona. La teleología de la formación es el desarrollo de todas las potencialidades humanas en un proceso de entrenamiento espiritual. Los estudios realizados tanto dentro como fuera del Instituto deben ayudar en este proceso humanizador (Cf. Las confesiones, X, VIII, 15).

La formación debe ayudar al desarrollo del hombre interior, el cual define el alguien que soy (cf. Sermón, 126, 4), y no simplemente al equipamiento y adiestramiento del hombre exterior, que define el algo que soy. La formación debe armonizar estas dos dimensiones antropológicas para poder alcanzar un desarrollo integral de la persona. Por ello, el objetivo esencial del proceso formativo es humanizar al hombre (Cf. La doctrina cristiana, XI, 12).

Desde esta perspectiva, para Agustín ser formador trasciende el ámbito de un oficio dado por los superiores. Debe ser una vocación que empuja desde dentro a realizar esta tarea en la que se cree y en cuya realización está toda la vida, tanto personal como del Instituto. Es una vocación definida por el amor, el cual es la motivación última que impulsa y mantiene su misión (Cf. Contra Fausto, XXXII, 18). Parafraseando a Agustín podemos sostener que formar es una especificidad humana que implica que "El formador trate a sus formandos con amor de hermano, con amor de padre, y hasta con amor de madre. Formador y formandos deben tener su morada los unos en los otros" (La catequesis a los principiantes, XII, 17). Sin esta actitud necesaria el formador terminará asumiendo el protagonismo del proceso formativo, objetualizando al formando quien deberá amoldarse a sus pre-juicios. Por tanto, la dinámica formativa ha de partir y desarrollarse a través de relaciones horizontales y complementarias entre los sujetos que interactúan, ya que necesitamos del otro para ser nosotros mismos (Cf. Comentario al Salmo, 125, 13).

La formación consiste en el entrenamiento de las capacidades espirituales, para hacer al hombre "libre de" sus tendencias interiores, dándole la posibilidad de comprender el "sentido" de las acciones (libertad para). Así, pues, formar es estimular al hombre para que sea consciente de su responsabilidad ante sí mismo, el otro y Dios, posibilitándole, con la fuerza del Espíritu, vivir su vocación originaria trastocada por el pecado original.

La formación, entendida como especificidad humana, es para Agustín un proceso interactivo y dialógico entre formador y formandos, en el cual el primero cumple la función mediadora entre la realidad personal de los formandos y el perfil agustiniano de nuestra Orden. Si el formador desconoce algunos 
de estas "dos orillas" no podrá establecer "un puente" que las una y, por tanto, imposibilitará el "paso" del formando de una a la otra, incumpliendo así su función mediadora. Para ello es necesario la apertura y asunción de disciplinas que nos ayuden en el alcance de este objetivo, como por ejemplo la psicología.

Otro elemento esencial de nuestro proceso formativo es su función socializadora. El formador debe enseñar al formando la identidad propia de nuestra Orden, así como su especificidad dentro de la Iglesia, para que éste pueda asumir las exigencias de este "grupo social". Por tanto, es condición necesaria e irrenunciable que las personas que tengan el servicio de ser formadores conozcan y vivan estos postulados, siendo testimonios vivientes de que el ideal que se pide vivir es posible vivirlo porque ellos lo viven.

En definitiva, el proceso formativo presupone una relación; un juego de libertades en el que el formador cultiva en el joven las semillas de humanidad, y el formando va adquiriendo, poco a poco y a lo largo de un camino interior, la autonomía, logrando identificarse con lo propio de nuestra vida agustiniana. Proceso formativo que se desarrolla a través de: (a) una relación dialógica y respetuosa entre los sujetos que interactúan; (b) la interioridad, la cual posibilita el conocimiento y dominio de sí para poder relacionarme con el otro desde la autenticidad; y (c) el auxilio del Espíritu, debido a que la todo este proceso de humanización es posible por la Gracia.

En el siguiente gráfico se expone, a modo de síntesis, los elementos y las condiciones del proceso formativo agustiniano.

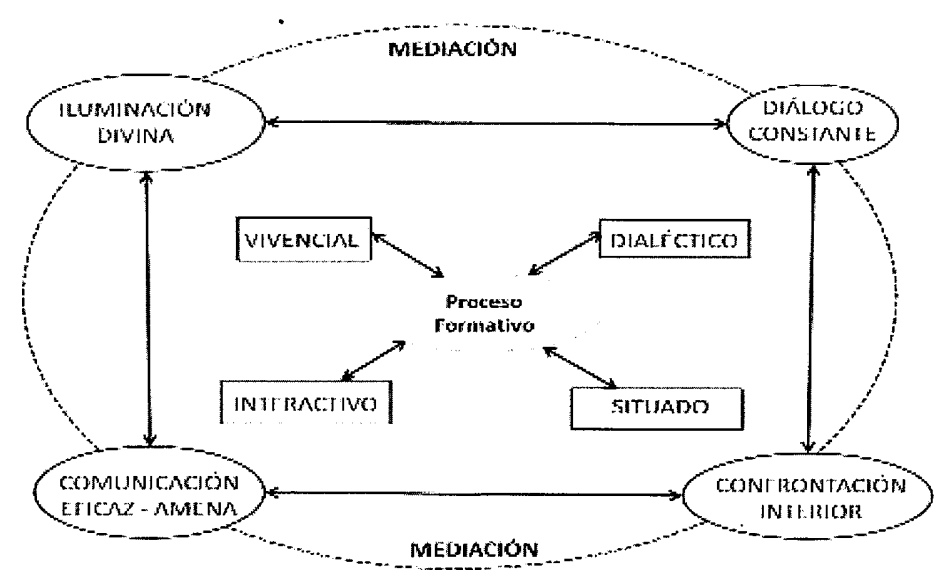

Gráfico $N^{\circ}$ 3. Elementos y condiciones del proceso formativo agustiniano (Totumo, C., 2012) 


\section{Elementos pedagógicos agustinianos}

Aunque en el apartado anterior se ha mencionado algo de la pedagogía agustiniana, en las siguientes líneas se tratará de exponer sistemáticamente algunos elementos pedagógicos que nos pueden ayudar a alcanzar el objetivo humanizador de nuestra formación.

\subsection{Formador y formandos son condiscípulos de Jesús, el único Maestro}

Cuando Agustín habla en las Confesiones de su transformante encuentro con Cristo expresa la razón por la cual no había encontrado a Dios; Dios estaba en él pero él no estaba consigo mismo y, por tanto, él no estaba con Dios. Estaba inmerso en el hombre exterior (Cf. X, XXVII, 38). Para llegar a Dios, Agustín tuvo que llegar primero a sí mismo. Es a través del conocimiento personal que Agustín llega a Dios. Interioridad y trascendencia están íntimamente relacionas.

Este camino de interioridad orientado a la trascendencia es lo que le permite al santo de Hipona conocerse a sí mismo y, a su vez, a Dios. Por ello, Agustín afirma de manera imperativa:

"No quieras derramarte fuera; entra dentro de ti mismo, porque en el hombre interior mora la Verdad. Y si encuentras lo que en tu naturaleza es mudable, trasciéndete a ti mismo. Pero no olvides que, al remontarte sobre las cimas de tu ser, te elevas sobre tu alma, dotada de razón. Encamina tus pasos allí donde la luz de la razón se enciende" (La verdadera religión, XXXIX, 72).

Como a la cita realizada se le puede objetar que estas palabras se refieren a la verdad gnoseológica, hay que afirmar que para Agustín la Verdad no es un algo sino una Alguien. Es Cristo, el cual es "Más íntimo que nuestra propia intimidad y más alto que los más alto de nuestro ser" (Las confesiones, III, VI, 11). Por tanto, la invitación agustiniana es hacer el paso del hombre exterior al hombre interior, no sólo para ser en autenticidad, sino para llegar a Cristo y dejarnos guiar por Él (Cf. El maestro, XI, 33). Los demás hombres solamente somos cooperadores, o en términos pedagógicos, somos mediadores en este encuentro. Sólo existe un único Maestro del cual todos somos condiscípulos. Tanto formador como formando deben tener una docilidad interior para escuchar la voz del Señor y para seguirle en humildad. Es por ello, que Agustín llega a afirmar:

Nosotros les hablamos desde el exterior, pero es Cristo, quien edifica desde dentro. Nosotros podemos saber cómo escuchas, pero cómo piensas sólo 
puede saberlo aquel que ve tus pensamientos. Es Él quien edifica, quien amonesta, quien amedranta, quien abre el entendimiento, quien los conduce a la fe; aunque nosotros cooperamos con nuestro esfuerzo (Comentario al salmo 126,2).

Tenemos un solo maestro. Y, bajo Él, somos todos condiscípulos. No nos constituimos en maestros por el hecho de hablarles desde un púlpito. El verdadero Maestro habla desde dentro (Sermón, 134,1,1).

A la luz de estas palabras de Agustín hay que sostener que: (a) la autoridad del formador no consiste en "poder de mando". Es un don que se le ha dado. Y como todo don, de él tendrá que dar cuenta (Cf. Sermón, 46, 2; Regla, VII, 46); (b) la relación entre formador y formando ha de ser horizontal, no vertical. Es decir, debe valorar a los formandos como sujetos que me aportan posibilidades para la creación de mi existencia; y viceversa; (c) formador y formando deben realizar un camino vital de interiorización para volver a sí mismos; (d) ambos deben tener una actitud de humildad y de escucha discipular al Maestro interior. Es decir, deben dejarse configurar por su Palabra; y (e) unidos en fraternidad caminamos juntos hacia Cristo. En consecuencia, la comunidad formativa, en particular, y toda comunidad agustiniana, en general, es una escuela de condiscípulos que caminan fraternalmente hacia Cristo, el maestro interior. Es un camino de búsqueda fraterna a través de una relación de libertades y un diálogo de voluntades. Solamente si está presente el amor a Cristo, formador y formandos pueden unirse y el proceso de formación adquirirá la verdadera dimensión y profundidad que le es propia.

\subsection{Función mediadora del formador}

Formar, de acuerdo a lo que se ha venido desarrollando, consiste en desplegar potencialidades y valores ya existentes en cada formando, así como el desarrollo de un camino discipular. Es, en definitiva, encender la luz interior del discípulo para que él mismo haga el descubrimiento de la Verdad. Es ayudar a desarrollar y potenciar la espontaneidad del formando, a sacar afuera sus posibilidades.

La función principal del formador consiste, según el santo, en acercar gradualmente al formando a su interioridad para que, desde ésta, él pueda llegar al Maestro interior. La palabra es el medio a través del cual el hombre revela a los otros lo que es y tiene, ya que "El hombre no puede unirse con firmeza a los otros, si no es por medio del lenguaje, y así es como si fundiesen sus mentes y sus pensamientos entre sí" (El orden, II, XII, 35). Ella "Incita al hombre a que descubra por sí mismo". (El maestro, XIV, 46). Por 
tanto, el formador es sólo un mediador o colaborador en el proceso que cada formando debe realizar. Camino interior que luego debe exteriorizarse en fraternidad.

En consecuencia, el formador tiene tres funciones interrelacionadas: enseñar, deleitar y mover. El enseñar se refiere a los contenidos que expresan nuestra historia e identidad; y el deleitar y mover se refieren al estímulo que deben potenciar en los formandos para que inicien con gozo y esperanza su camino (Cf. La doctrina cristiana, IV, XII, 27). La finalidad de la formación es despertar el hombre interior, "Porque ¿quién de los hombres sabe las cosas del hombre sino el espíritu del hombre, que está dentro de él?" (La ciudad de Dios, XIV, VI, 2).

El formador no es el Maestro, sino un condiscípulo portador de estímulos y un suministrador de herramientas para facilitar el encuentro consigo mismo, con Dios y con el otro. Su función prioritaria es crear en el formando la actitud de buscador enamorado de la Verdad. Para ello, el formador debe crear un ambiente favorable que facilite el alcance de estos objetivos.

En definitiva, la función mediadora del formador consiste en establecer un puente que una la realidad personal de los formandos y lo propio de nuestra vida agustiniana. Si el formador desconoce algunos de estas "dos orillas" no podrá establecer este puente. Por el contrario, será un obstáculo que imposibilite el "paso" del formando de una a la otra, incumpliendo así su función mediadora. Para ello es necesaria la formación continua del formador, así como una actitud de humildad y de oración.

\subsection{Autoridad moral}

El alcance de la función mediadora del formador, desde la perspectiva agustiniana, no se alcanza a través de un mero cumplimiento externo de lo establecido. Él debe ser prueba fidedigna de que es posible vivir lo que propone porque él lo vive. La única autoridad que tiene es vivir lo que predica. Por tanto, el término autoridad moral se refiere a la coherencia entre el ser, el hacer y el decir.

Agustín, en la obra Del trabajo de los monjes, una vez expuesto los argumentos bíblicos referentes al significado material de la frase paulina "El que no trabaje que no coma" ( 2 Tes. 3,10$)$, invita a los monjes a evaluar en su vida la coherencia entre sus palabras y sus acciones:

No arrojo sobre ustedes cargas pesadas ni abrumo sus hombros con pesos que con ni un dedo quiera tocar yo. Pregunten e infórmense de la fatiga de 
mis ocupaciones, de los achaques de mi salud para ciertos trabajos, de las costumbres de las Iglesias a cuyo servicio vivo (XXIX, 37).

En consecuencia, otra de las actitudes necesarias del formador es la constante auto-evaluación e inclusive la co-evaluación, desde la corrección fraterna, para poder cumplir su función mediadora.

\subsection{Respetar y estimular la singularidad de cada formando}

Desde los cuatro elementos pedagógicos desarrollados hay que afirmar que la formación, desde la perspectiva agustiniana, ha de ser un proceso personalizado, porque debe considerar la realidad existencial de los formandos; y personalizador, porque se ha de formar para la libertad y la autonomía invitando a vivir de manera consciente lo que profundamente ya se es: ser humano. San Agustín afirma al respecto que "Hay que dar a todos el mismo amor, pero no se puede dar a todos la misma medicina" (La catequesis a los principiantes, XV;23). Formar es desplegar la propia originalidad de cada formando y provocar el empeño por la realización de un proyecto discipular de vida. En palabras de Mounier (1990), la meta de la educación no es hacer sino despertar personas. El objetivo fundamental de la pedagogía agustiniana es ayudar al sujeto a que sea dueño de sí mismo. Es ayudar a ser verdaderamente libres, es decir, a ser dueños y señores del propio mundo interior y de la propia voluntad (Cf. El libre albedrío, III, 33), para poder vivir sabia e inteligentemente.

El formador debe evitar hacer divisiones excluyentes dentro de la comunidad formativa, lo cual crea divisiones en los mismos formandos. Es frecuente encontrar en las comunidades formativas aquel formador que centra su atención en un grupo de formandos, descuidando a los demás. Al respecto, Agustín sostiene que el formador, debido a su vocación y a la creencia profunda en el hombre, cuando se consigue con personas que tienen dificultad para emprender el camino discipular propuesto debe "Armarse de misericordia y paciencia" (Cf. La catequesis a los principiantes, XIII, 18) para acompañarlo en su proceso personal y prestarle el andamiaje necesario. El Sermón a los pastores es expresión de esto, incluso en él se sostiene que al pastor que no cumple su función Cristo, el único pastor, le quitará su rebaño.

\section{Espiritualidad agustiniana}

He querido dejar como último apartado de esta ponencia el desarrollo de la espiritualidad agustiniana no porque ella sea poco importante, sino por- 
que es lo que posibilita todo lo anterior. No hay que olvidar que la propuesta pedagógica agustiniana es una propuesta cristiana de humanización. Es el Espíritu quien posibilita que el hombre llegue y se conozca a sí mismo, y lo introduce en una dinámica trinitaria. El criterio hermenéutico para ver si una determinada espiritualidad es cristiana o no, es si ella potencia un proceso de humanización.

Los autores que hablan sobre la espiritualidad agustiniana tienen tanto diferencias como similitudes entre sí. Todo depende de cuál sea el elemento que consideren más importante y cuáles omiten. Por ende, solamente haré una propuesta de lo que puede denominarse espiritualidad a la luz de la concepción antropológica y la experiencia espiritual de Agustín.

La espiritualidad agustiniana está constituida por seis dimensiones agrupadas en tres binas, relacionadas entre sí: (a) interioridad - trascendencia; (b) comunidad - eclesialidad; y (c) estudio - Escritura.

\section{a. Interioridad}

Esta dimensión es netamente antropológica. Para Agustín, el camino para que el hombre se conozca a sí mismo y pueda crear su existencia en autonomía y libertad es la interioridad. El hombre debe entrar en sí para poder dar el paso del hombre exterior al hombre interior. Por ende, es un dinamismo de introspección para sondear el profundo mar interior y poder encontrar nuestro tesoro para dinamizarlo y permitir que los demás contemplen nuestra hermosura. Al respecto, san Agustín expresa: "¡Cuántas riquezas no oculta el hombre dentro de sí! Pero, ¿de qué le sirven si no sondea e investiga?" (Comentario al Salmo, 76, 9).

El hombre debe dejar de ser vivido por las cosas exteriores a él, y tomar la valentía de agarrar el timón de su vida a través del autoconocimiento y aceptación personal. Sin embargo, hay que afirmar que este dinamismo interior no lo realiza el hombre con sus propias fuerzas, sino auxiliado por el Espíritu Santo, el cual nos ayuda a alcanzar nuestro orden (Cf. Las confesiones, XIII, IX, 9). Sólo el que "Anda por dentro desea las cosas de dentro. Andar por fuera es desechar las cosas de dentro y llenarse de las de fuera (Tratado sobre el evangelio de san Juan, XXV,15).

La experiencia agustiniana de interioridad queda magistralmente expuesta en las Confesiones, en la cual Agustín realizada una mirada retrospectiva de su vida a la luz de la fe para evaluar su vida desde la cercanía o alejamiento de Dios. Es por ello, que en el libro IX, I, 1, expresa en que consistía 
todo el problema existencial de conversión: "En dejar de querer lo que yo quería y empezar a querer lo que querías Tú".

\section{b. Trascendencia}

Esta segunda dimensión de la espiritualidad agustiniana está en relación directa con la interioridad. Es esta segunda dimensión la que permite afirmar que el volver a nosotros mismos no consiste en un solipsismo, es decir, un encerramiento del yo en sí mismo. La interioridad agustiniana es totalmente distinta a un solipsismo por dos razones. Primero porque conociéndome a mí mismo conozco al otro porque "Soy humano y nada de lo humano me es ajeno" (Carta, 78, 8); y, segundo, porque al entrar en mí reconozco que yo no soy causa de mi ser, sino que soy por otro. Soy por Dios. Es un ser por participación. Por tanto me abro a la trascendencia. El hombre es un sistema abierto a la trascendencia. Agustín sostiene esto a través de las siguientes palabras:

"No quieras derramarte fuera; entra dentro de ti mismo, porque en el hombre interior mora la Verdad. Y si encuentras lo que en tu naturaleza es mudable, trasciéndete a ti mismo. Pero no olvides que, al remontarte sobre las cimas de tu ser, te elevas sobre tu alma, dotada de razón. Encamina tus pasos allí donde la luz de la razón se enciende" (La verdadera religión, XXXIX, 72).

Incluso, como Dios es más íntimo que nuestra propia intimidad (Cf. Las confesiones, III, VI, 11) y nos enseña desde nuestro interior (Cf. Sermón, 134, 1,1 ), el hombre debe volver a sí mismo para poder llegar a Dios. Agustín, convencido de esto, afirma que él no había encontrado a Dios porque no se había encontrado a sí mismo. Porque estaba inmerso en el hombre exterior, extasiado por la cosas externas.

Tú estabas dentro de mí y yo fuera, y por fuera te buscaba; y deforme como era, me lanzaba sobre estas cosas hermosas que tú creaste. Tú estabas conmigo, más yo no estaba contigo. Me retenían lejos de ti aquellas cosas que, si no estuviesen en ti, no existirían (Las confesiones, X, XXVII, 38).

Estas dos primeras dimensiones de la espiritualidad agustiniana permiten afirmar que ella posibilita un proceso humanizador integral. Me posibilita hacerme cargo de mi existencia y abrirme al Ser que me ha creado orientado hacia Él (Cf. Las confesiones, I, I, 1). Por tanto, el acercamiento a Dios no implica una enajenación del ser humano y la religión no es el "opio del pueblo". Al encontrar a Cristo, Agustín encuentra en superlativo todo lo que andaba buscando (Cf. Las confesiones, IX, I, 1). Dios no sólo toca su alma, 
orientándola hacia Él. Es todo el ser humano quien está orientado hacia Dios. Esto lo expresa Agustín a través de los cinco sentidos: (a) auditivo: llamaste y clamaste, y rompiste mi sordera; (b) visual: brillaste y resplandeciste, y fugaste mi ceguera; (c) olfato: exhalaste tu perfume y respiré, y suspiro por ti; (d) gusto: gusté de ti, y siento hambre y sed; y (e) tacto: me tocaste, y ardo en deseos de tu paz (Cf. Las confesiones, X, XXVII, 38).

Quiero culminar la exposición de esta segunda dimensión con las siguientes palabras de Agustín, las cuales revelan la relación intrínseca de la interioridad con la trascendencia: “¿Cómo te busco pues Señor? Porque al buscarte, Dios mío, busco la felicidad. Te buscaré, Señor, para que viva mi alma. Mi cuerpo vive de mi alma, y mi alma vive de Ti" (Las confesiones, X, XX, 29).

\section{c. Comunidad - fraternidad}

El dinamismo existencial y trascendente no se reduce a un encuentro excluyente del hombre con Dios. Es una dinámica trinitaria: Yo, Dios y el otro. Los hombres caminan como condiscípulos hacia Cristo, el único maestro. Por ende, la comunidad agustiniana es una escuela fraterna de discípulos de Cristo.

Agustín sabe por experiencia propia que toda relación interpersonal se da en un dinamismo de tensión. La prueba de esto es el tema del trigo y la cizaña que aparece en varias de sus obras, así como el capítulo IV de nuestra Regla dedicado a la corrección fraterna. Las siguientes palabras agustinianas son iluminadoras en el tema en cuestión: "Todo hombre es prójimo del hombre, y no debe pensarse en diferencias marginales donde la naturaleza es común" (Comentario al Salmo, 118, 8, 2).

La comunidad agustiniana no es ni una residencia estudiantil, ni un grupo de amigos que se reúnen para pasarlo bien. Es una escuela discipular unida por el Espíritu de Cristo, quien posibilita superar las diferencias personales. Al respecto, Agustín afirma que "No hay verdadera amistad sino cuando tú, Señor, la estableces como un vínculo entre las almas que se unen mutuamente por medio del amor derramado en nuestros corazones por el Espíritu Santo que se nos ha dado" (Las confesiones, IV, IV, 7). Incluso, el santo de Hipona llega a afirmar que "El amor fraterno no es sólo don de Dios, sino Dios mismo" (Tratado sobre la Trinidad, VIII, 12).

\section{d. Eclesialidad}

La comunidad agustiniana está en relación con la Iglesia porque para Agustín la comunidad religiosa tiene como finalidad profética mostrar a la 
Iglesia lo que está llamada a vivir: un camino discipular de servicio fraternal. Por ello, Agustín concibe la autoridad como servicio.

En lo que respecta a las comunidades religiosas, Agustín expresa esta concepción de autoridad con las siguientes palabras: "El que los preside, que no se sienta feliz por mandar con autoridad, sino por servir con caridad" (Regla, VII, 46). Y en lo que respecta al nivel eclesial, Agustín sostiene que los pastores deben hacerse cargo de sus ovejas (Cf. Sermón, 46) y las ovejas deben rezar por sus pastores y ayudarse entre sí (Cf. Sermón, 47). Esta unidad fraternal de la Iglesia la expresa Agustín a través de dos concepciones eclesiológicas: el Cristo total (totus Christus) y la Iglesia madre.

Agustín, siguiendo la analogía eclesiológica paulina del cuerpo, sostiene que la Iglesia es el cuerpo de Cristo. El totus Christus es la unión de la Cabeza y los miembros del cuerpo. Al respecto el santo de Hipona afirma que "Nosotros somos Cristo porque somos sus miembros, y su cuerpo por ser Él nuestra cabeza, por ser el Cristo total (totus Christus) la cabeza y el cuerpo" (Sermón, 133, 8).

En consecuencia, esta noción eclesiológica agustiniana se basa en la cristología, y expresa una doble relación: (a) de pertenencia: el cuerpo es cuerpo de Cristo y; (b) de identidad: los miembros deben reconocer que es Cristo quien da unidad y sentido a todo el cuerpo. Por ende, todos los miembros están orientados hacia Cristo. No hay espacio para colocarse por encima de los demás. Sólo hay una única cabeza.

En lo que respecta a la segunda noción eclesiológica agustiniana, Agustín sostiene que la Iglesia es madre debido a que nos da la vida a través del sacramento del bautismo, nos alimenta con la Eucaristía (Cf. Sermón, 216, $7,7)$ y nos conduce con misericordia al encuentro con el Padre en Cristo Jesús. Por ende, los cristianos tiene el deber de cuidar, amar y defender a la Iglesia, su madre (Cf. Comentario al Salmo, 88, 2,14).

\section{e. Estudio}

La importancia del estudio para Agustín se puede ver en su formación académica, en su práctica docente y en su gran producción literaria. Sin embargo hay que tener claro cuál es el sentido agustiniano del estudio. Para él todo proceso epistémico debe estar orientado a la realización del ser humano. No se trata de conocer por conocer, sino conocer al sujeto que conoce.

Para Agustín, el hombre es un ser buscador apasionado de la Verdad, la cual llega a vislumbrar, pero nunca alcanzar en su totalidad (Cf. Tratado sobre la Trinidad, XI, I, 1; XV, II, 2). La inquietud existencial y el consiguiente afán y empeño por hallar la Verdad apetecida, le impulsan a volcarse hacia el inte- 
rior de sí mismo porque es allí donde se la puede encontrar (Cf. La verdadera religión, XXXIX, 72; El maestro, XI, 38; XII, 39).

$\mathrm{El}$ verdadero conocimiento consiste en conocerse a sí mismo. El conocimiento del mundo y de las cosas solamente tienen sentido en tanto contribuyan al primero. Agustín escribe al respecto que:

Los hombres salen a hacer turismo para admirar las crestas de los montes, el oleaje proceloso de los mares, el fácil y copioso curso de los ríos, las revoluciones y los giros de los astros. Y, sin embargo, se pasan de largo a sí mismos (Las confesiones, X, VIII, 15).

En consecuencia, para Agustín no es lo mismo ser racional que ser sabio. $\mathrm{El}$ "racional" es aquel que conoce y almacena un vasto conocimiento en su memoria, pero sin ninguna repercusión de éste en la vida del sujeto que los posee. Por el contrario, el hombre "sabio" es aquel que se conoce a sí mismo, y desde su interioridad conoce y aprende todo lo demás. Al respecto, Agustín expresa que "Llamamos sabios a quienes... mediante el gobierno de su espíritu, han conquistado la paz" (El libre albedrío, I, 69). El estudio es un medio para llegar a la sabiduría.

En este sentido, la finalidad de la educación es, para San Agustín, un medio para "despertar" y estimular al sujeto a que se "levante" e inicie un proceso de exploración y conocimiento interior. Se ha de educar para la libertad y la autonomía invitando al educando a vivir de manera consciente lo que profundamente ya es: ser humano. Por tanto, en el proceso epistémico educativo mente y corazón están estrechamente unidos.

\section{f. Sagrada Escritura}

La importancia de la Sagrada escritura para Agustín se puede ver solamente con leer las obras agustinianas, en las cuales las citas bíblicas abundan por doquier. Ella es la autoridad. Cuando lo eligen para ser ordenado presbítero, lo único que pide Agustín es tiempo para estudiar y meditar las Sagradas Escrituras (Cf. Carta, 21, 3). El cristiano debe ser un hombre de la Palabra.

La sistematización de esta espiritualidad agustiniana no puede terminar en la exposición de estas seis dimensiones. Si fuese así quedaría la sensación de un pelagianismo subyacente: el hombre puede lograr por sus propias fuerzas el proyecto planteado. Por ello, estas dimensiones se enmarcan en un contexto trinitario.

El termino "espiritualidad" hace referencia a que es el Espíritu de Jesús de Nazaret el que nos posibilita y guía en este dinamismo multidimensional. En términos paulinos, espiritualidad es la vida según el Espíritu (Cf. 1Cor.3,1; 
Rom. 7, 5-6), el cual nos permite tener los mismos sentimientos de Cristo Jesús (Flp. 2,5), llamar Abba a Dios (Gal. 4,6) y decir Jesucristo es Señor (1Cor. 12,3). Por tanto, es el Espíritu quien nos lleva a Cristo y al Padre, así como a nosotros mismos.

A modo de conclusión de esta cuarta parte de la ponencia presento a continuación el siguiente gráfico en donde se pueden apreciar la interrelación entre todas las dimensiones y su marco trinitario. Por ende, tomar una de las dimensiones implica tomar las demás.

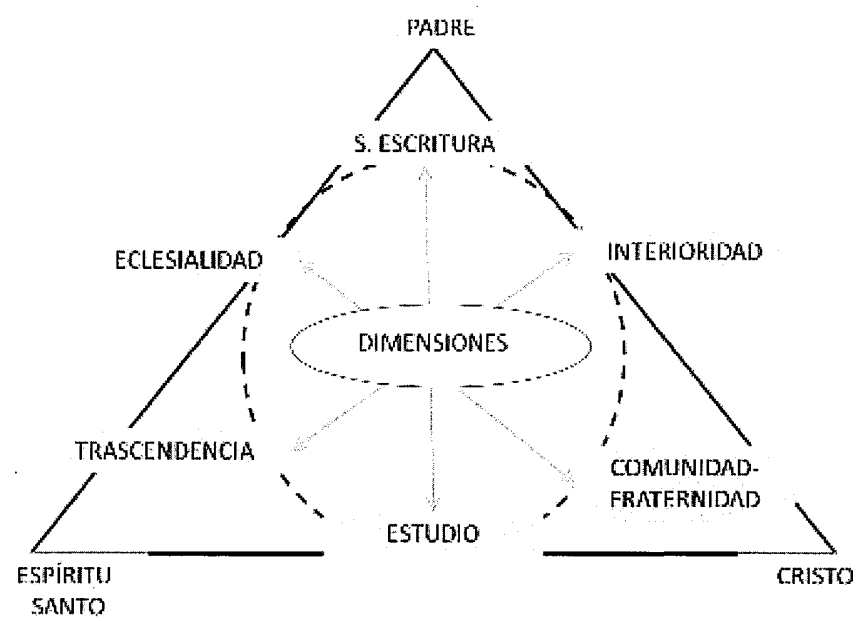

Gráfico $N^{\circ}$ 4. Dimensiones de la espiritualidad agustiniana (Totumo, C., 2012)

Quiero concluir el desarrollo de este tema pidiendo a Dios, nuestro Padre, que renueve en nosotros la fuerza de su Santo Espíritu para que, siguiendo los pasos de san Agustín, podamos vivir nuestro camino fraterno de discipulado a Cristo siendo testigos y testimonio de su presencia entre nosotros y podamos "Dar razón de nuestra esperanza" (1 Pe. 3, 15). Amén. 


\section{REFERENCIAS BIBLIOGRÁFICAS}

Agustín, SAn (2008). Regla. En Regla y Constituciones de la Orden de san Agustín. Roma: Curia General Agustiniana.

Agustín, SAN (1964). Comentarios sobre los Salmos I (76-117). En Obras completas de San Agustín: Vol. 19. Madrid: BAC.

Agustín, SAN (1967). Comentarios sobre los Salmos IV (118-150). En Obras completas de San Agustin: Vol. 22. Madrid: BAC.

Agustín, SAN (1968). Tratado sobre la Trinidad. En Obras completas de San Agustín: Vol. 5. Madrid: BAC.

Agustín, SAN (1968). Tratados sobre el Evangelio de San Juan (1-35). En Obras completas de San Agustín: Vol. 13. Madrid: BAC.

Agustín, SAN (1969). Del trabajo de los monjes. En Obras completas de San Agustín: Vol. 12. Madrid: BAC.

Agustín, San (1969). El orden. En Obras completas de San Agustín: Vol. 1 (4ta. ed.). Madrid: BAC.

Agustín, SAn (1969). La doctrina cristiana. En Obras completas de San Agustín: Vol. 15 (2da. ed.). Madrid: BAC.

Agustín, SAN (1969). Soliloquios. En Obras completas de San Agustín: Vol. 1 (4ta. ed.). Madrid: BAC.

Agustín, SAn (1971). El libre albedrío. En Obras completas de San Agustín: Vol. 3 (4ta. ed.). Madrid: BAC.

Agustín, SAn (1971). El maestro. En Obras completas de San Agustín: Vol. 3 (4ta. ed.). Madrid: BAC.

Agustín, San (1974). Las confesiones. En Obras completas de San Agustín: Vol. 2 (6ta. ed.). Madrid: BAC.

Agustín, SAn (1975). La verdadera religión. En Obras completas de San Agustín: Vol. 4 (3ra. ed.). Madrid: BAC.

Agustín, SAn (1981). Sermones I (1-50). En Obras completas de San Agustín: Vol. 7. Madrid: BAC.

Agustín, SAn (1983). Sermones III (117-183). En Obras completas de San Agustín: Vol. 23. Madrid: BAC.

Agustín, San (1986). Cartas I (1-123). En Obras completas de San Agustín: Vol. 8. Madrid: BAC.

Agustín, SAN (1988). La catequesis a los principiantes. En Obras completas de San Agustín: Vol. 39. Madrid: BAC.

Agustín, San (1993). Contra Fausto. En Obras completas de San Agustín: Vol. 31. Madrid: BAC.

Agustín, SAn (2001). La ciudad de Dios II. En Obras completas de San Agustín: Vol. 17. Madrid: BAC.

Berdón, E. (coord.) (2008). Elementos básicos de pedagogía agustiniana. Perú: Biblioteca Básica Familiar Agustiniana.

FreIRE, P. (1997). Pedagogía de la autonomía. México: Edt. Siglo XXI. 
Mounier, E. (1990). Obras completas: Vol. 3. Salamanca: ed. Sígueme.

Rodríguez, L. (1978). El maestro de Casiciaco. Estudio Agustiniano, 13 (1), pp. 115-120.

Totumo, C. (2012). Aproximación al ideario pedagógico de san Agustín. Iquitos Perú: OALA. 